\title{
ESTABLISHMENT OF NEW FITTED GEOID MODEL IN UNIVERSITI TEKNOLOGI MALAYSIA
}

\author{
M. K. Ismail ${ }^{1}$, A. H. M. Din ${ }^{1,2,3, *}$, M. N. Uti ${ }^{1}$, A. H. Omar ${ }^{1}$ \\ ${ }^{1}$ Geomatics Innovation Research Group (GIRG), ${ }^{2}$ Geoscience and Digital Earth Centre (INSTEG), Faculty of Built Environment \\ and Surveying, Universiti Teknologi Malaysia, 81310 Johor Bahru, Johor, Malaysia. -* amihassan@utm.my \\ ${ }^{3}$ Associate Fellow, Institute of Oceanography and Environment (INOS), Universiti Malaysia Terengganu, Kuala Terengganu, \\ Terengganu, Malaysia
}

KEY WORDS: MyGEOID, gravimetric geoid, fitted geoid

\begin{abstract}
:
The purpose of this study is to produce fitted geoid for Universiti Teknologi Malaysia (UTM), Johor Bahru by using precise levelling and 3D GNSS control network technique. This study focuses on the theory, computation method and analysis of fitted geoid around Universiti Teknologi Malaysia. The computation of accuracy fitted geoid model is based on the GNSS levelling and Precise Levelling. The achieved accuracy of UTM Fitted Geoid Model is at $8 \mathrm{~mm}$. In conclusion, this research can contribute to Universiti Teknologi Malaysia by providing good UTM fitted geoid model that can give better accuracy for various purposes of work related to surveying and mapping.
\end{abstract}

\section{INTRODUCTION}

\subsection{Research Backgrounds}

For decades, one of the main studies in Science of Geodesy is precise geoid determination (Nordin, 2009). Jabatan Ukur dan Pemetaan Malaysia (DSMM), also known as the Department of Survey and Mapping Malaysia (DSMM) has implemented a project to map the geoid with the main objective to produce high precise geoid in order to determine the geoid height across the country in 2002 . The geoid can be broadly defined as an equipotential surface of Earth's gravity field that closely approximates with mean sea level (MSL) neglecting long term effect of sea surface topography (Singh et al., 2007). Geoid determination includes collecting the gravity data over a wide area. In order to collect gravity data, DSMM has conducted an Airborne Gravity and Geoid Mapping Project across East and West Malaysia (Jamil, 2011).

Research institutes and agencies responsible for geodetic positioning have spent millions of dollars to precisely determine the local and regional geoid using GNSS. Also, terrestrial gravity data, satellite altimeter data, global geoid models and digital terrain model were used in the calculation of the geoid model Malaysia. Furthermore, GNSS levelling has managed to simulate the vertical datum bias and further correspondence issued geoid (geoid fitted) with the vertical datum that is based on the mean sea level. This study area will focus on Universiti Teknologi Malaysia, Johor Bahru as shown in Figure 1.

The aim of this study is to produce a localised fitted geoid for Universiti Teknologi Malaysia (UTM), Johor Bahru using the combination of precise levelling and three dimensional GNSS network techniques. The main problem of this study is the insufficient fitting point from the existing fitted geoid model, which is MyGEOID in UTM area. Less density of fitting point will affect the accuracy of the geoid fitting to give better solutions for height measurements. The benefits of this study are the determination of local precise geoid models (UTM fitted geoid) by using more intensive data that will support the less density of fitting points from MyGEOID. This research intended to prove that local fitted geoid (UTM fitted geoid) can have better results compared to the existing fitted geoid model of MyGEOID.

Generally, the achievable accuracy of the fitted geoid from MyGEOID in Peninsular Malaysia is around $5 \mathrm{~cm}(1 \sigma)$. This accuracy can be increased by increasing the density of the fitting points observed by GNSS levelling at benchmark.

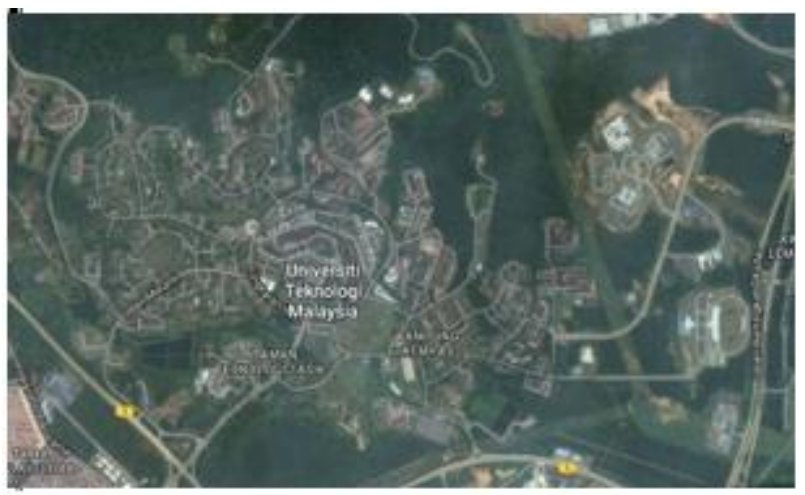

Figure 1. The Map of UTM (Google Maps, 2017).

\subsection{MyGEOID}

MyGEOID is the product that was produced for first Malaysian geoid model (DSMM, 2005). It is able to compute orthrometric height $\mathrm{H}$, referred to as the national geodetic vertical datum (NGVD). It contains the height of geoid $\mathrm{N}$ relative to the reference ellipsoid GRS80 surface in the form of a grid. The geoid determination of Malaysia is based on the available gravimetry (airborne, surface and satellite altimetry), which is

\footnotetext{
*amihassan@utm.my
} 
continued downward to the surface of the topography, after removal of a spherical harmonic reference field expansion (DSMM, 2008). In addition, it consists of two geoid models, which are WMGEOID04 for Peninsular Malaysia and EMGEOID05 for Sabah and Sarawak as illustrated in Figure 2 and 3, respectively. The achievable accuracy with MyGEOID is around $5 \mathrm{~cm}(1 \sigma)$ and $10 \mathrm{~cm}(1 \sigma)$ for Peninsular Malaysia and Sabah and Sarawak, respectively. However, claimed accuracy of DSMM of MyGEOID is only representative of an entire general region without concerning how it represents a small area (DSMM, 2005).

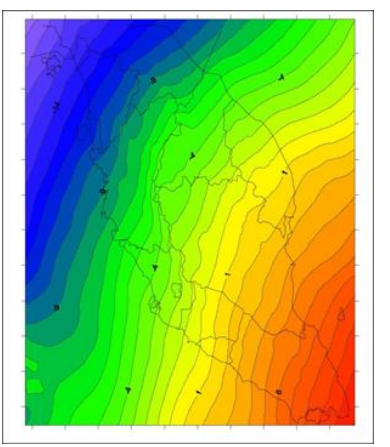

Figure 2. Peninsular Malaysia Fitted Geoid 2004 (WMGEOID04), (DSMM, 2005)

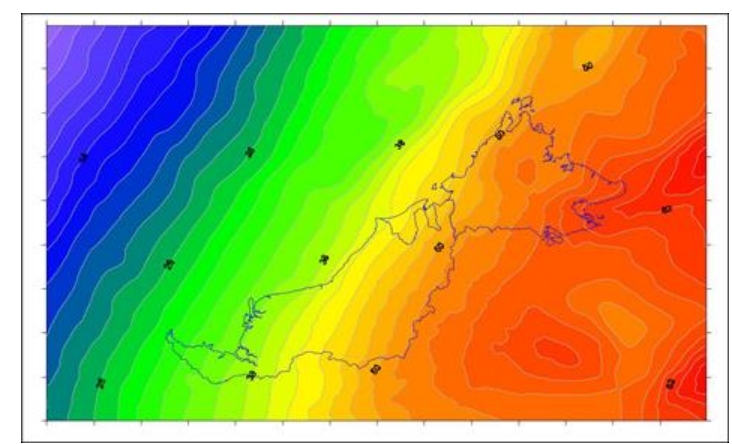

Figure 3. Sabah and Sarawak Fitted Geoid 2005 (EMGEOID05), (DSMM, 2005)

\subsection{Precise levelling}

Precise Levelling is a precise form of differential levelling, where differential levelling is defined as the operation of determining differences in elevation of points some distance apart of established benchmarks (BM), which use highly accurate and a more rigorous observing procedure than general engineering levelling (Mui, 2006). From this method, 1D control network can establish a UTM fitted geoid model around UTM area. Process by using precise levelling method run for the measurement of elevation is considered the most accurate method to produce the best quality results in fitted geoid levelling. According to (DSMM, 2009), the reading of precise level is acceptable if the observation misclosure is lower than the allowable misclosure where,

Allowable misclosure

$=0.003(\mathrm{~m}) * \sqrt{ } \mathrm{K}$

$K$ is the levelling distance in $\mathrm{km}$

Observation misclosure

= Observed height - initial/known

\subsection{GNSS Levelling 3D Network}

Department of Survey and Mapping Malaysia (DSMM) has established GNSS infrastructure in Malaysia as a reference control stations for cadastral and mapping purposes. With the increasing potential of Global Navigation Satellite System (GNSS) satellites and its calculation techniques, determination of height using GNSS has been widely used to replace the geometric levelling. By using GNSS levelling technique, knowing the geoidal height $\mathrm{N}$, the orthometric height $\mathrm{H}$ can be calculated from ellipsoidal height $h$. Deriving orthometric height using this technique with certain level of accuracy could replace conventional spirit levelling and therefore make the levelling procedures cheaper and faster (Abu, 2005). The interpolated geoidal heights are the prerequisite for deriving orthometric or normal heights from GNSS heights without levelling (Ihde, 2009). From GNSS observation, we can establish the 3D control network around UTM.

The aim of this paper is to establish new fitted geoid model in UTM in order to increase the reliability of fitted geoid model from MyGEOID. It is also aimed to determine how good the new fitted geoid model represents small region, especially in UTM, by using precise levelling and 3D control network technique using GNSS observation and Gravimetric geoid data.

\section{DATA AND METHODS}

A general overview of the process for this study is shown in Figure 4. The process is mainly divided into four main steps: (1) research area identification; (2) data acquisition; (3) data processing; (4) data verification. The list of software used in this study are STAR*NET for precise levelling processing and adjustment, Trimble Business Centre (TBC) for GNSS data processing and Golden Surfer Software for data interpolation, fitting and plotting.

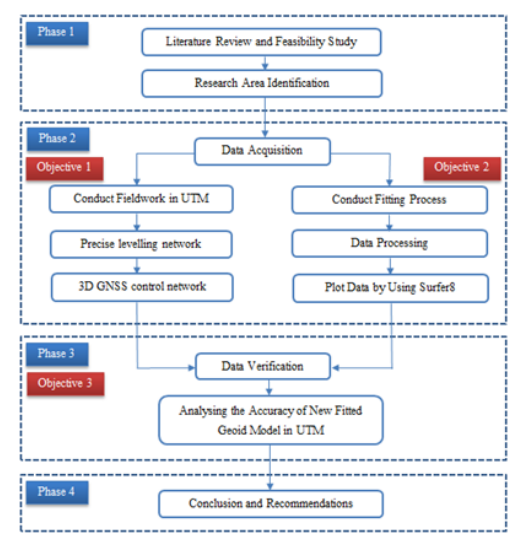

Figure 4. General overview of the process

\subsection{Establishment of the Mean Sea Level (MSL) Height Using Precise Levelling}

19 benchmarks were established covering UTM area $(2 \mathrm{~km} \mathrm{x}$ $2 \mathrm{~km})$. The MSL heights were transferred from standard benchmark J4352 in UTM, located at Faculty Alam Bina (FAB), to all 19 benchmarks. Verification of benchmark is carried out to ensure the accuracy of the benchmark. Establishing benchmark requires good distribution position of benchmark since the benchmark will later be used for GNSS observation. The known value for standard benchmark J4352 FAB in UTM is shown in Table 1. 


\begin{tabular}{|c|c|c|}
\hline No & Name & Hmsl (m) \\
\hline 1 & J4352 FAB & 24.3813 \\
\hline \multicolumn{3}{|c|}{ Table 1. Benchmark known value } \\
\hline
\end{tabular}

The precise levelling planning network contains 21 levelling routes, 3 levelling loops and 1 network as shown in Figure 5.

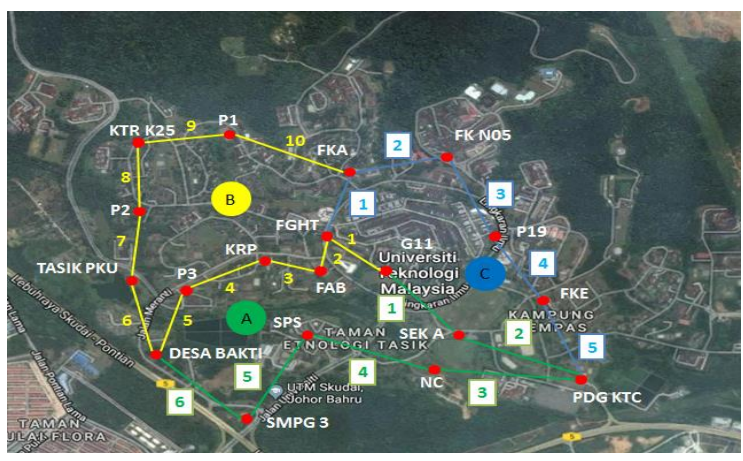

Figure 5. Precise levelling planning

\subsection{GNSS levelling using 3D Control Network}

A GNSS network consists of 19 point that have been observed on established benchmark using five TOPCON GR5 dual frequency receivers. There are several important factors that need to be considered in designing 3D control network:

-Design good network geometry

-Acquire control within project area

-Incorporate independent baselines

Static GNSS observation (1 hour) method is applied for all observations located at UTM. The GNSS data is processed by using network processing in TBC software. Only independent baselines were processed between 19 stations. The 3D control networks for GNSS levelling are connected with 3 Malaysian Real Time Kinematic Network (MyRTKnet) stations, which are JHJY, KUKP and SPGR. Baselines were processed between P1, P2, P3, KTR, FKA, FKN05, PKU, DESA BAKTI, SMPG 3, SPS, G11, NC, SEK AGAMA, FKE, KTC, P19, KRP, FGHT and FAB. The observed baselines are shown in Figure 6, while holding 3 CORS, which are JHJY, KUKP and SPGR, as fixed in latitude, longitude and ellipsoidal height. Then, adjusted coordinates (latitude, longitude and ellipsoidal height) were generated for each target point.

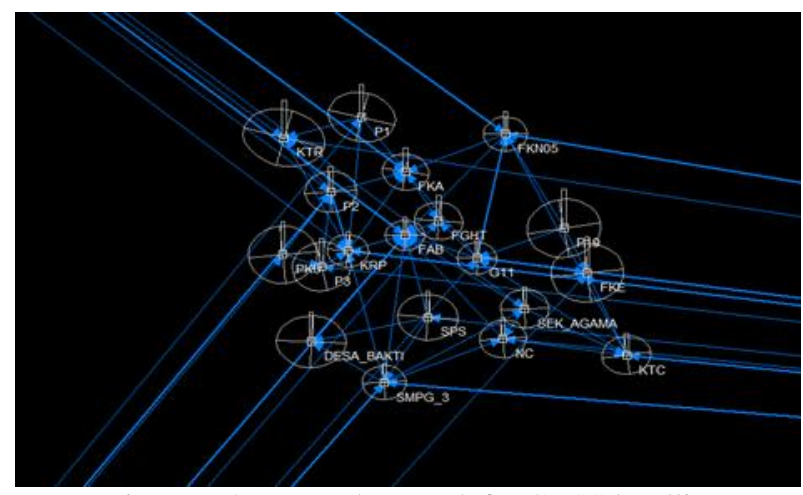

Figure 6. 3D control network for GNSS levelling.

\subsection{Gravimetric Geoid Retrieval from MyGEOID}

Gravimetric geoid is one of the MyGEOID's products that can be retrieved from DSMM. MyGEOID provides data with size 1' by $1^{\prime}(1.8 \mathrm{~km} \times 1.8 \mathrm{~km})$ covering Malaysia. In this case, in order to obtain the gravimetric geoid data at the established temporary benchmark, Golden Surfer software is used to extract the data. There are several interpolation methods to transform point data and each of them can have different results, however, it is important to determine which one give better solution in terms of accuracy (Anonym, 1999). Thus, in Golden Surfer process, Kringing method is used because it fits the data better (Erol and Celik, 2004).

\subsection{Vertical Datum Bias (VDB) computation at the selected} points

VDB can be derived from Equation 1:

$$
V D B=h_{G N S S}-H_{M S L}-N_{\text {gravimetric }}
$$

where,

$V D B=$ vertical datum bias

$H_{G N S S} \quad$ ellipsoidal height from GNSS

$H_{M S L} \quad=$ mean sea level height

$N_{\text {gravimetric }} \quad=$ gravimetric geoid height

In selecting reference points, keeping the homogeneous distribution of reference points set were considered. Ten points are selected. These points will later be used to perform the fitting process.

\subsection{Fitting Process using Gravimetric Geoid Surface to MSL Surface}

In order to determine the UTM Fitted Geoid model for local area, gravimetric surface must be shifted to MSL surface using this Equation:

Fitted geoid surface $=$ gravimetric geoid + VDB

Latitude, longitude, fitted geoid value of selected reference points is later used in Golden Surfer software to form a fitted geoid model.

\section{RESULTS AND ANALYSIS}

\subsection{Establishment of MSL height using precise levelling}

The MSL height from precise level for every benchmark point is shown in Table 2. Meanwhile, the accuracy validation for precise levelling data for loop A, B, C and network are shown in Table 3.

\begin{tabular}{|c|c|}
\hline Point & H $_{\text {MSL }}($ Precise Level) $(\mathbf{m})$ \\
\hline FAB & 24.0735 \\
\hline J4352 FAB ${ }^{*}$ & $\mathbf{2 4 . 3 8 1 3}$ \\
\hline FGHT & 31.2047 \\
\hline G11 & 34.1924 \\
\hline FKA & 32.8176 \\
\hline FKN05 & 45.6844 \\
\hline P19 & 17.5326 \\
\hline FKE & 21.5504 \\
\hline
\end{tabular}




\begin{tabular}{|c|c|}
\hline KTC & 10.1496 \\
\hline SK. AGAMA & 12.3042 \\
\hline KRP & 25.3805 \\
\hline P3 & 21.6278 \\
\hline DESA BAKTI & 40.2542 \\
\hline PKU & 17.3573 \\
\hline P2 & 30.2430 \\
\hline KTR & 28.8775 \\
\hline P1 & 24.0867 \\
\hline NC & 14.6368 \\
\hline SPS & 22.0038 \\
\hline SMPG 3 & 23.3116 \\
\hline
\end{tabular}

Table 2. MSL heights from precise level for every benchmark point

From Table 2, the value of $\mathrm{H}_{\mathrm{MSL}}$ from each point are obtained by using the precise levelling method starting from the standard benchmark of J4352. Thus, three survey loops are proposed in order to cover the area.

\begin{tabular}{|c|c|c|}
\hline & Error Factor & Lower/Upper Bounds \\
\hline Loop A & 0.451 & $(0.933 / 1.067)$ \\
\hline Loop B & 0.147 & $(0.933 / 1.066)$ \\
\hline Loop C & 0.149 & $(0.941 / 1.059)$ \\
\hline Network & 0.254 & $(0.947 / 1.053)$ \\
\hline
\end{tabular}

Table 3. Error factor for 3 loops and a network from precise levelling

\subsection{GNSS levelling using 3D Control Network}

To achieve precise coordinate for points on BM's, GNSS observations were made and the products are in geographical coordinates and ellipsoidal heights. This $3 \mathrm{D}$ control network is used mainly for horizontal control but also from this GNSS observation, the by-product, which is the ellipsoidal height, is essential for GNSS levelling purpose or in other words, height modernization.

The accurate geographical coordinates for $19 \mathrm{BM}$ were obtained by processing the GNSS data in TBC software whilst observed by Topcon GR5 receivers. 3 MyRTKnet Stations have been used as reference point, which is JHJY, KUKP and SPGR. The results indicate the accurate position of BM points that used static mode observation. The coordinates and ellipsoidal heights for each BM are shown in Table 4. Table 5 tabulates the standard deviations of latitude, longitude and ellipsoidal height using one sigma.

\begin{tabular}{|c|c|c|c|}
\hline Point & $\begin{array}{c}\text { Latitude } \\
(\mathbf{N})\end{array}$ & Longitude (E) & $\begin{array}{c}\text { Ellipsoidal } \\
\text { Height (m) }\end{array}$ \\
\hline D. BAKTI & 1.553818442 & 103.628932039 & 48.0975 \\
\hline FAB & 1.559434797 & 103.633504150 & 31.9451 \\
\hline FGHT & 1.560203256 & 103.635142094 & 39.0865 \\
\hline FKA & 1.562772872 & 103.633530664 & 40.6949 \\
\hline FKE & 1.557442469 & 103.642396089 & 29.4773 \\
\hline FKN05 & 1.564777667 & 103.638422289 & 53.5814 \\
\hline G11 & 1.558222575 & 103.637042869 & 42.0802 \\
\hline KRP & 1.558617947 & 103.630726553 & 35.2246 \\
\hline KTC & 1.553098078 & 103.644327039 & 18.0662 \\
\hline
\end{tabular}

\begin{tabular}{|c|c|c|c|}
\hline KTR & 1.564582675 & 103.627622161 & 36.8121 \\
\hline NC & 1.553961694 & 103.638291981 & 22.532 \\
\hline P1 & 1.565662417 & 103.631393794 & 32.3133 \\
\hline P19 & 1.559813533 & 103.641271614 & 25.4622 \\
\hline P2 & 1.561725797 & 103.629889503 & 38.0959 \\
\hline P3 & 1.557757317 & 103.629434800 & 29.4751 \\
\hline PKU & 1.558412686 & 103.627543425 & 25.2043 \\
\hline SK. AGAMA & 1.555557900 & 103.639359678 & 20.2124 \\
\hline SMPG 3 & 1.551658406 & 103.632488739 & 31.1815 \\
\hline SPS & 1.555096933 & 103.634615622 & 29.8804 \\
\hline
\end{tabular}

Table 4. Coordinates and ellipsoidal height for each BM

\begin{tabular}{|c|c|c|c|}
\hline Point & $\begin{array}{c}\text { Latitude } \boldsymbol{\sigma} \\
(\mathbf{m m})\end{array}$ & $\begin{array}{c}\text { Longitude } \\
\boldsymbol{\sigma}(\mathbf{m m})\end{array}$ & $\begin{array}{c}\text { Ellipsoidal } \\
\text { Height } \boldsymbol{\sigma} \\
(\mathbf{m m})\end{array}$ \\
\hline D. BAKTI & 2.5 & 3.0 & 3.9 \\
\hline FAB & 2.0 & 2.3 & 3.2 \\
\hline FGHT & 2.2 & 2.6 & 3.9 \\
\hline FKA & 2.2 & 2.7 & 3.9 \\
\hline FKE & 2.9 & 3.5 & 5.0 \\
\hline FKN05 & 2.2 & 2.7 & 3.7 \\
\hline G11 & 2.1 & 2.6 & 3.6 \\
\hline KRP & 2.1 & 2.6 & 3.5 \\
\hline KTC & 1.9 & 2.4 & 3.1 \\
\hline KTR & 2.8 & 3.6 & 5.0 \\
\hline NC & 2.0 & 2.3 & 3.2 \\
\hline P1 & 2.6 & 3.2 & 4.7 \\
\hline P19 & 2.9 & 3.4 & 5.2 \\
\hline P2 & 2.4 & 2.9 & 4.1 \\
\hline P3 & 2.5 & 2.9 & 4.3 \\
\hline PKU & 2.9 & 3.3 & 4.8 \\
\hline SK. AGAMA & 2.0 & 2.4 & 3.2 \\
\hline SMPG 3 & 1.8 & 2.2 & 3.0 \\
\hline SPS & 2.2 & 2.7 & 3.5 \\
\hline Tab 5t
\end{tabular}

Table 5. Standard deviations of latitude, longitude and ellipsoidal height for one sigma

\subsection{Gravimetric geoid from MyGEOID}

Gravimetric geoid, obtained from Airborne Gravity and Geoid Determination carried out by DSMM, is a geoid of undisturbed characteristic. The gravimetric geoid data is one of the MyGEOID products. The value was then interpolated or modelled by using Golden Surfer software. Figure 7 shows the model or geoid contour map generated by Golden Surfer software for Gravimetric Geoid data. Only small difference of geoid undulation can be observed from the map.

\section{Gravimetric Geoid for UTM Area}

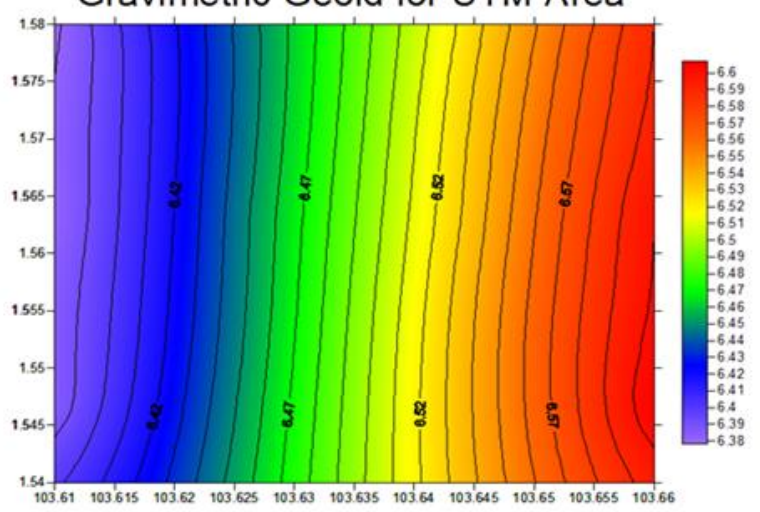

Figure 7. Gravimetric Geoid of MyGeoid in UTM area. 
From Table 6, we can see that the values of gravimetric geoid or $\mathrm{N}_{\text {Gravimetric }}$ for UTM area are around $6 \mathrm{~m}$ with only difference at decimal points. The points also were extracted by using Golden Surfer software. We can conclude that height separation of ellipsoid and geoid in this area is around $6 \mathrm{~m}$ and the values are positive indicating that the level surface of ellipsoid is below the equipotential surface.

\begin{tabular}{|c|c|}
\hline Point & N Gravimetric (m) \\
\hline D. BAKTI & 6.464388305 \\
\hline FAB & 6.483959362 \\
\hline FGHT & 6.491219557 \\
\hline FKA & 6.482943422 \\
\hline FKE & 6.526103495 \\
\hline FKN05 & 6.504363441 \\
\hline G11 & 6.500747451 \\
\hline KRP & 6.471396452 \\
\hline KTC & 6.536908602 \\
\hline KTR & 6.455682096 \\
\hline NC & 6.508167736 \\
\hline P1 & 6.472228308 \\
\hline P19 & 6.519628862 \\
\hline P2 & 6.466778449 \\
\hline P3 & 6.465623309 \\
\hline PKU & 6.456661689 \\
\hline SK. AGAMA & 6.512616053 \\
\hline SMPG 3 & 6.481734234 \\
\hline SPS & 6.490562775 \\
\hline
\end{tabular}

Table 6. The gravimetric geoid value interpolated of extracted from MyGEOID model

\subsection{Computation of Vertical Datum Bias}

The vertical datum bias (VDB) can be represented by the difference or separation between the Mean Sea Level and Geoid (gravimetric) level surface. For the computation of VDB, the general formula is shown in Equation 1. Ten points were chosen for the fitting process and become the fitting point so computations for vertical datum bias only for the selected points as shown in Table 7. The range of the vertical datum bias at UTM, also known as Sea Surface Topography, is approximately $1 \mathrm{~m}$. The results indicated that the separation of MSL and Geoid level surface is around $1 \mathrm{~m}$ difference. It is generally known that geoid is said to coincide with the MSL surface, yet the difference is significant.

\begin{tabular}{|c|c|}
\hline Point & Vertical Datum Bias (m) \\
\hline DESA BAKTI & 1.378921695 \\
\hline FAB & 1.387680638 \\
\hline FGHT & 1.390620443 \\
\hline FKA & 1.394336578 \\
\hline FKE & 1.400766505 \\
\hline KTR & 1.478877904 \\
\hline NC & 1.387022264 \\
\hline P2 & 1.386111551 \\
\hline P3 & 1.381656691 \\
\hline SPS & 1.386047225 \\
\hline
\end{tabular}

Table 7. Vertical Datum Bias at selected points

\subsection{Fitting process}

To realize the height modernisation system concept, a fitting process has been conducted. Fitting is the process of shifting the geoid of gravimetric surface to MSL surface by eliminating the
SST or VDB culminating in a continuous level surface called fitted geoid. The UTM Fitted Geoid model is the product of height modernisation system and modelled by Golden Surfer software. Prior to fitting, a total of ten selected points (VDB points) are used along with their respective accurate position. After applying the VDB to the gravimetric geoid height, ten fitting points are produced. Fitted geoid surface can be calculated by using Equation 2 as shown below:

$$
N_{\text {fitted }}=N_{\text {gravimetric }}+V D B
$$

$$
\begin{array}{ll}
\text { where, } & \\
N_{\text {fitted }} & =\text { fitted } \text { geiod height } \\
N_{\text {gravimetric }} & =\text { gravimetric geoid height } \\
V D B & =\text { vertical datum bias }
\end{array}
$$

Based on Table 8, the values of Geoid height are between the ranges of approximation of $8 \mathrm{~m}$. These are only for the points of fitting and by putting aside temporarily the other ten points for further use, these points are used to produce the model of UTM fitted Geoid contour map. The differences are only in sub-meter level throughout the area in UTM.

The model of final product of height modernisation is depicted in Figure 8. The main objective of having UTM Fitted Geoid model has been realised. The geoid separation or undulation is ranged between $7.8 \mathrm{~m}$ to $8.0 \mathrm{~m}$ from the map. This map is produced from the same prior software which is Golden Surfer.

\begin{tabular}{|c|c|c|c|}
\hline Point & Latitude (N) & $\begin{array}{c}\text { Longitude } \\
(\mathbf{E})\end{array}$ & $\begin{array}{c}\text { N Fitted } \\
(\mathbf{m})\end{array}$ \\
\hline D.BAKTI & 1.553818442 & 103.628932 & 7.84331 \\
\hline FAB & 1.559434797 & 103.6335042 & 7.87164 \\
\hline FGHT & 1.560203256 & 103.6351421 & 7.88184 \\
\hline FKA & 1.562772872 & 103.6335307 & 7.87728 \\
\hline FKE & 1.557442469 & 103.6423961 & 7.92687 \\
\hline KTR & 1.564582675 & 103.6276222 & 7.93456 \\
\hline NC & 1.553961694 & 103.638292 & 7.89519 \\
\hline P2 & 1.561725797 & 103.6298895 & 7.85289 \\
\hline P3 & 1.557757317 & 103.6294348 & 7.84728 \\
\hline SPS & 1.555096933 & 103.6346156 & 7.87661 \\
\hline
\end{tabular}

Table 8. Value of $\mathrm{N}$ fitted and positions at selected fitting points

\section{UTM Fitted Geoid for UTM Area}

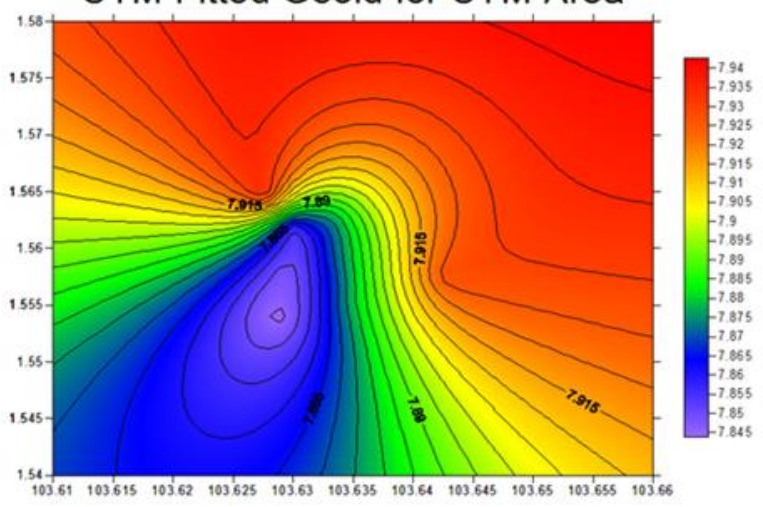

Figure 8. Contour map of UTM Fitted Geoid

\subsection{Analysing the accuracy of UTM Fitted Geoid}

To analyse the external accuracy of the UTM fitted geoid, a set of external data or the other ten points that are not fitted are used for assessment. To realise this assessment, the seven points 
of non-fitted are extracted and interpolated from the UTM geoid model. The value of $\mathrm{N}_{\text {fitted }}$ is represented by Table 9 .

\begin{tabular}{|c|c|c|c|}
\hline Point & Latitude (N) & $\begin{array}{c}\text { Longitude } \\
(\mathbf{E})\end{array}$ & $\begin{array}{c}\mathbf{N} \\
\text { Fitted(m) }\end{array}$ \\
\hline PKU & 1.558412686 & 103.6275434 & 7.85591 \\
\hline SMPG 3 & 1.551658406 & 103.6324887 & 7.86221 \\
\hline G11 & 1.558222575 & 103.6370429 & 7.89270 \\
\hline SK.AGAMA & 1.5555579 & 103.6393597 & 7.90414 \\
\hline FKN05 & 1.564777667 & 103.6384223 & 7.90964 \\
\hline KTC & 1.553098078 & 103.644327 & 7.91616 \\
\hline P19 & 1.559813533 & 103.6412716 & 7.91849 \\
\hline
\end{tabular}

Table 9. Value of positions and $\mathrm{N}_{\text {fitted }}$ for external accuracy points.

Referring to Table 9, the value of $\mathrm{N}_{\text {fitted }}$ for other unfitted points extracted from the UTM Geoid Model shows the value of approximately $8 \mathrm{~m}$ with difference not exceeding a meter level. Then, the assessment continues by deriving a geoid called geometric geoid. For the external accuracy points, a set of geometric geoid points were computed by applying Equation 3.

$$
N_{\text {geometric }}=h_{G N S S}-H_{M S L}
$$

where,

$$
\begin{array}{ll}
N_{\text {geometric }} & =\text { geometric geoid height } \\
h_{G N S S} & =\text { ellipsoidal height from GNSS } \\
H_{M S L} & =\text { mean sea level height }
\end{array}
$$

After applying the aforementioned formula, a set of geometric geoid height, or $\mathrm{N}_{\text {geometric, }}$ is derived as shown in Table 10. The main function of $\mathrm{N}_{\text {geometric }}$ is to evaluate and verify the external accuracy of the fitted geoid in UTM. In other words, $\mathrm{N}_{\text {geometric }}$ is for verifying geoid.

\begin{tabular}{|c|c|c|c|}
\hline Point & Latitude (N) & $\begin{array}{c}\text { Longitude } \\
(\mathbf{E})\end{array}$ & $\begin{array}{c}\mathbf{N} \\
\text { Geometric } \\
(\mathbf{m})\end{array}$ \\
\hline PKU & 1.558412686 & 103.6275434 & 7.84697 \\
\hline SMPG 3 & 1.551658406 & 103.6324887 & 7.86993 \\
\hline G11 & 1.558222575 & 103.6370429 & 7.88785 \\
\hline SK.AGAMA & 1.5555579 & 103.6393597 & 7.90817 \\
\hline FKN05 & 1.564777667 & 103.6384223 & 7.89701 \\
\hline KTC & 1.553098078 & 103.644327 & 7.91662 \\
\hline P19 & 1.559813533 & 103.6412716 & 7.92958 \\
\hline
\end{tabular}

Table 10. The positions and value of $\mathrm{N}_{\text {geometric }}$ for external accuracy points.

\section{Geometric Geoid for UTM Area}

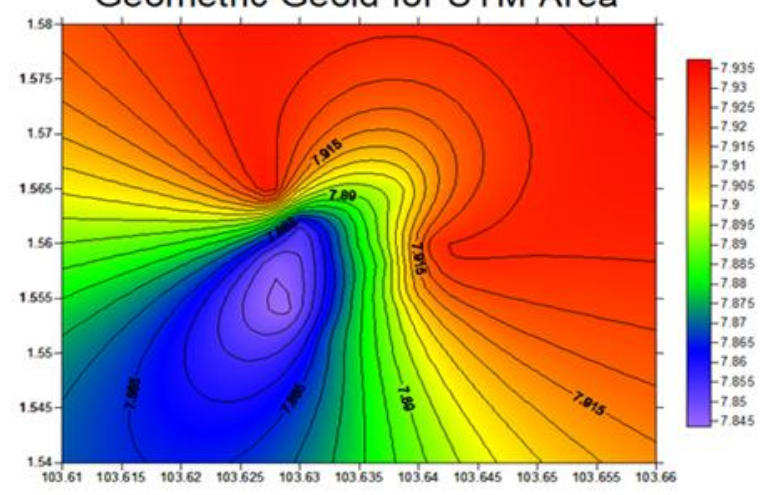

Figure 9. Contour map of Geometrics geoid model.
These values of $\mathrm{N}_{\text {geometric }}$ from Table 10 are later compared to the $\mathrm{N}_{\text {fitted }}$ at the same points from Table 9. The differences are called external accuracy, which depict the accuracy of the UTM Geoid Model. Equation 4 as shown below is applied to get the difference:

External Accuracy $(x)=N_{\text {fitted }}-N_{\text {geometric }}$

where,

$N_{\text {fitted }}=$ fitted geoid height interpolated from UTM Geoid $N_{\text {geometric }}=$ geometric geoid height

From Table 11, the difference of $\mathrm{N}_{\text {fitted }}$ and $\mathrm{N}_{\text {geometric }}$ can be said to be less than around $1 \mathrm{~cm}$ accuracy difference. This difference should later be presented in Root Mean Square Error (RMSE) value. The biggest difference comes from FKN05, which give the value of $12 \mathrm{~mm}$, and the smallest difference is KTC, which

\begin{tabular}{|c|c|c|c|}
\hline Point & $\begin{array}{c}\text { Mean sea } \\
\text { level height } \\
\left(\mathbf{H}_{\text {GNSS }}\right) \text { by } \\
\text { using UTM } \\
\mathbf{N}_{\text {fitted }}(\mathrm{m})\end{array}$ & $\begin{array}{c}\text { Mean sea } \\
\text { level height } \\
\left(\mathbf{H}_{\mathrm{MSL}}\right) \\
\text { precise } \\
\text { level }(\mathrm{m}) \\
\end{array}$ & $\begin{array}{l}\text { Difference } \\
\text { (m) }\end{array}$ \\
\hline PKU & 17.3484 & 17.3573 & 0.009 \\
\hline SMPG 3 & 23.3193 & 23.3116 & 0.008 \\
\hline G11 & 34.1875 & 34.1924 & 0.005 \\
\hline SK.AGAMA & 12.3083 & 12.3042 & 0.004 \\
\hline FKN05 & 45.6718 & 45.6844 & 0.013 \\
\hline KTC & 10.1500 & 10.1496 & 0.0004 \\
\hline P19 & 17.5437 & 17.5326 & 0.011 \\
\hline & & RMSE (m) & 0.008 \\
\hline
\end{tabular}
is only $0.4 \mathrm{~mm}$. The RMSE actually depicts the overall accuracy of the project. According to Table 11, the accuracy of the UTM fitted geoid is at $8 \mathrm{~mm}$.

Table 11. RMSE value from the comparison of Mean Sea Level from UTM $\mathrm{N}_{\text {fitted }}\left(\mathrm{H}_{\mathrm{GNSS}}\right)$ with Mean Sea Level from precise levelling $\left(\mathrm{H}_{\mathrm{MSL}}\right)$

\subsection{Mean Sea Level (MSL) comparison between MyGEOID} and precise levelling

Based on the calculation of RMSE between the $\mathrm{H}_{\mathrm{GNSS}}$ and $\mathrm{H}_{\mathrm{MSL}}$ in Table 11 , the error is about $8 \mathrm{~mm}$, which is smaller than the RMSE value from the comparison of Mean Sea Level from MyGEOID and precise levelling, which is about $8 \mathrm{~cm}$ as shown in Table 12. This result has proved that the level computation from localised UTM fitted geoid is much better compared with the MyGEOID.

\begin{tabular}{|c|c|c|c|}
\hline Point & $\begin{array}{c}\text { Mean sea } \\
\text { level height } \\
\left(\mathbf{H}_{\text {GPS }}\right) \mathbf{b y} \\
\text { using } \\
\text { MyGEOID } \\
\mathbf{N}_{\text {fitted }}(\mathbf{m})\end{array}$ & $\begin{array}{c}\text { Mean sea } \\
\text { level height } \\
\mathbf{( H}_{\text {MSL }} \\
\text { precise } \\
\text { level (m) }\end{array}$ & $\begin{array}{c}\text { Difference } \\
(\mathbf{m})\end{array}$ \\
\hline PKU & 17.4418 & 17.3573 & 0.084 \\
\hline SMPG 3 & 23.3949 & 23.3116 & 0.083 \\
\hline G11 & 34.2754 & 34.1924 & 0.083 \\
\hline SK.AGAMA & 12.3961 & 12.3042 & 0.092 \\
\hline FKN05 & 45.7735 & 45.6844 & 0.089 \\
\hline KTC & 10.2261 & 10.1496 & 0.077 \\
\hline
\end{tabular}




\begin{tabular}{|c|c|c|c|}
\hline P19 & 17.6392 & 17.5326 & 0.107 \\
\hline \multicolumn{3}{|c|}{ RMSE (m) } & 0.088 \\
\hline
\end{tabular}

Table 12. RMSE value from the comparison of Mean Sea Level from MyGEOID $\mathrm{N}_{\text {fitted }}\left(\mathrm{H}_{\mathrm{GPS}}\right)$ with Mean Sea Level from precise levelling $\left(\mathrm{H}_{\mathrm{MSL}}\right)$

\section{CONCLUSION}

The establishment of UTM fitted geoid has been achieved successfully with RMSE value for external accuracy of $8 \mathrm{~mm}$. The results and analysis prove that height modernisation of GNSS levelling and Fitted Geoid is a very efficient means of height system. This is alternative for conventional tedious levelling even though the accuracy of GNSS levelling itself is relatively lower than the precise level. GNSS levelling can be applied to engineering survey works and other projects that take only centimetre level of accuracy into account.

\section{ACKNOWLEDGEMENTS}

The authors would like to thank to Department of Surveying and Mapping Malaysia (DSMM) for providing the MyGEOID Data. We are grateful to the Ministry of Education (MOE) Malaysia and Universiti Teknologi Malaysia for funding this research under Research University Grant (VOT number: Q.J130000.2527.19H26).

\section{REFERENCES}

Abu, S., 2005. Malaysia precise geoid (MyGEOID). Retrieved Sept 2005, from http://mycoordinates.org/malaysia-precisegeoid-mygeoid/all/1/.

Anonym, 1999. Golden Software, Surfer 8, User Guide: Contouring and 3D surface mapping for scientist and engineers, Colorado, USA

Erol, B., Çelik, R. N., 2004. Modelling Local GNSS/Levelling Geoid with the Assesstment of Inverse Distance Weighting and Geostatistical Kriging Methods. Technical Report, Istanbul Technical University-Civil Engineering Faculty, Istanbul, Turkey

Ihde, J., 1995. Geoid Determination by GNSS and Levelling. International Association of Geodesy Symposia Gravity and Geoid, 519-528.doi:10.1007/978-3-642-79721-7_55.

Department of Surveying and Mapping Malaysia (DSMM), 2008. Final Report on Height Modernisation System of Klang Valley. Lembah Klang, Selangor (Unpublished)

Department of Surveying and Mapping Malaysia (DSMM), 2005. Garis Panduan Penggunaan Model Geoid Malaysia (MyGEOID). Pekeliling Ketua Pengarah Ukur Dan Pemetaan Bil. 10, Kuala Lumur, Malaysia.

Department of Surveying and Mapping Malaysia (DSMM), 2009. Pekeliling Ketua Pengarah Ukur dan Pemetaan Bil. 6. Kuala Lumpur, Malaysia.

Jamil, H., 2011. GNSS Heighting and Its Potential Use in Malaysia. In GNSS Processing and Anallysis. Maarakehm Morocco: FIG Working Week 2011.
Mui, A., 2006. Deformation Monitoring Technique and Relationship between Vertical Control and Precision of Accuracy. School of Surveying and Spatial Information Systems, University of New South Wales, Australia.

Nordin, S., 2009. Height Modernization Using Fitted Geoid Models and MyRTKnet (master's thesis). Universiti Teknologi Malaysia, Johor, Malaysia.

Singh, S. K., Nagarajan, B. B. \& Garg, P. K. (2007). Retrieved Feb 2007, from http://mycoordinates.org/determination-oflocal-gravimetric-geoid/all/1/.

Revised August 2018 